\title{
Long-term prothionamide compliance: a study carried out in India using a combined formulation containing prothionamide, dapsone and isoniazid $\ddagger$
}

\author{
G A ELLARD,* K U KIRAN† \& J N A STANLEY $† \S$ \\ * National Institute for Medical Research, London NW7 1AA, \\ England; †Dhoolpet Leprosy Research Centre, Hyderabad 500006 , \\ Andhra Pradesh, India
}

\section{Accepted for publication 1 October 1987}

\begin{abstract}
Summary A comprehensive study of the self-administration of prothionamide is described in which over 2000 urine samples were collected from some 60 South Indian patients over a 2-year period. Prothionamide $(350 \mathrm{mg})$ was prescribed for daily self-administration as the commercially available combined formulation 'Isoprodian' that also contains dapsone and isoniazid. Drug ingestion was monitored by testing the samples qualitatively and quantitatively for the presence of the isoniazid metabolites acetylisoniazid and isonicotinic acid, and for dapsone together with its diazotisable metabolites.

About a third of the patients suffered from moderate or severe gastrointestinal side-effects attributed to prothionamide but no hepatic toxicity was encountered, whether or not treatment was supplemented with monthly supervised doses of rifampicin. The results obtained using the different urine-test methods correlated well and it was concluded that overall just over half the prescribed doses had been ingested. Although enormous variations in individual patient compliance were demonstrated, there was a continuous spectrum of drug taking and patients could not be simply grouped into good or poor compliers.

Older patients took their prescribed treatment less regularly. The compliance of patients who suffered from severe gastrointestinal side-effects was markedly impaired and improved when daily thioamide treatment was replaced by dapsone. The proportion of positive urine tests among samples collected at the patients' monthly clinic visits was similar to those collected by means of surprise home visits.

It was concluded that if prothionamide is used as an alternative to clofazimine in the multidrug treatment of lepromatous leprosy its compliance should be monitored using an isoniazid-marked formulation.
\end{abstract}

$\S$ Present address: Department of Postgraduate Medicine, University of Keele, Stoke-on-Trent, England.

$\ddagger$ Dedicated to the memory of Han Huikeshoven 


\section{Introduction}

It is recommended that multibacillary patients who find clofazimine skin pigmentation unacceptable should be treated with daily self-administered doses of dapsone $(100 \mathrm{mg})$ and ethionamide or prothionamide (250-375 mg) plus monthly supervised doses of $600 \mathrm{mg}$ rifampicin for at least 2 years. ${ }^{1}$ Experimental studies of the 2 thioamides in the mouse footpad ${ }^{2-4}$ and investigations of their pharmacokinetics in $\operatorname{man}^{5-7}$ indicate that their clinical potencies are likely to be very similar. The decision as to which one to employ would therefore appear to depend on their relative acceptability, toxicity, availability and cost.

Both thioamides were widely used for the treatment of pulmonary tuberculosis prior to the introduction of rifampicin. Gastrointestinal side-effects were common, although prothionamide appeared to be somewhat better tolerated. ${ }^{8}$ However, the daily dosages used $(500-1000 \mathrm{mg})$ were higher than that recommended for leprosy. Little is known of the acceptability and side-effects of the thioamides when given in lower dosages, although recent reports of their hepatotoxicity when combined with rifampicin give cause for concern. ${ }^{9-12}$

Experimental studies in the mouse footpad have demonstrated that when ethionamide was administered once a week its bactericidal activity was abolished..$^{13}$ Regular drug ingestion will therefore be essential to ensure that treatment failures caused by the multiplication of rifampicinresistant Mycobacterium leprae ${ }^{14,15}$ are prevented.

We recently reported a pilot cross-over study of ethionamide and prothionamide compliance among leprosy outpatients in Hyderabad, India. ${ }^{16}$ About three-quarters of the prescribed thioamide doses were ingested, and daily doses of $125 \mathrm{mg}$ ethionamide, and 125 or $250 \mathrm{mg}$ prothionamide were of similar acceptability to the patients. Furthermore, prothionamide and dapsone could be given together in a single daily capsule without compromising the dapsone compliance of the patients.

Although these results were encouraging, only 12 patients were studied and 2 of the patients (both heavy drinkers) developed jaundice. We therefore concluded that ethionamide or prothionamide could not be confidently recommended for the treatment of multibacillary leprosy until more extensive investigations of their compliance and hepatic toxicity had been undertaken. This paper reports such an investigation.

\section{Methods}

TREATMENT OF PATIENTS AND DESIGN OF THE STUDY

\section{Choice of patients}

Sixty patients (44 male, 16 female) who lived within an $8 \mathrm{~km}$ radius of the Dhoolpet Leprosy Research Centre, had received treatment at the Centre for at least a year, were judged to be likely to continue treatment for at least 2 years more, and were willing to allow clinic staff to visit their homes were enrolled in the study. Their ages ranged from 13-65 years (mean 37 years), they weighed from $20-96 \mathrm{~kg}$ (mean $46 \mathrm{~kg}$ ) and they had been previously treated for an average of 4 years, primarily with dapsone monotherapy. Forty were lepromatous ( $23 \mathrm{LL}$ and $17 \mathrm{BL}), 1$ borderline and 19 tuberculoid (13 BT and 6 TT).

The study was not a controlled clinical trial in a therapeutic sense since all patients were prescribed the same total net treatment. Furthermore, during the course of the study all patients were given at least 12 supervised monthly doses of rifampicin to ensure that the vast majority of any remaining viable leprosy bacilli would be rapidly killed..$^{1,14,17}$

\section{Initial run-in phase}

All patients were treated for 12 weeks with self-administered dapsone therapy (one $100 \mathrm{mg}$ tablet daily). 


\section{Cross-over phase}

The 60 patients were then assigned to 3 consecutive 24-week treatment schedules consisting of: (A) daily self-administered prothionamide $(350 \mathrm{mg})$ plus dapsone $(100 \mathrm{mg})$ plus isoniazid $(350 \mathrm{mg})$ using 2 tablets of the commercial combined formulation 'Isoprodian'; (B) the same treatment supplemented by monthly supervised doses of $600 \mathrm{mg}$ rifampicin; and (C) daily self-administered dapsone (one $100 \mathrm{mg}$ tablet) plus monthly supervised doses of $600 \mathrm{mg}$ rifampicin.

Ten patients were assigned by random allocation to each of the 6 possible sequences (ABC, $\mathrm{ACB}, \mathrm{BAC}, \mathrm{BCA}, \mathrm{CAB}$ and $\mathrm{CBA}$ ) in which the 3 regimens could be administered.

\section{Final phase}

All the patients continued treatment for a further 24 weeks with daily self-administered dapsone plus monthly supervised rifampicin (regimen C).

\section{MANAGEMENT OF SIDE-EFFECTS}

Patients who experienced gastrointestinal side-effects attributed to prothionamide treatment were given short courses of antacid or antiemetic treatment, reassured and encouraged to continue treatment. However, if their symptoms persisted, and the patient objected strongly to continuing Isoprodian treatment, it was replaced by daily dapsone plus monthly rifampicin. Any patient who developed jaundice or serum glutamic transaminase levels in excess of 90 units/litre was to be immediately withdrawn from the study.

\section{SUPERVISION OF TREATMENT, GIVING OF TEST ISOPRODIAN DOSES AND COLLECTION OF BLOOD AND URINE SAMPLES}

The patients were encouraged to visit the clinic once every 4 weeks when they were seen by the doctor and any side-effects that might have been attributable to the treatment recorded. The monthly rifampicin dose was swallowed, a urine sample collected and tablets of Isoprodian or dapsone issued for the following month for ingestion first thing each morning. A second urine sample was obtained each month by means of a surprise home visit using a randomized home visiting schedule. Blood samples were taken on alternate clinic visits for routine transaminase estimations.

On a single prearranged occasion during the initial run-in period, each patient was visited in their home, a urine sample was collected and a test dose of Isoprodian ( 2 tablets) was swallowed in place of that day's dapsone tablet. Further urine samples were then collected after $24,48,72$ and $96 \mathrm{~h}$.

\section{ANALYTICAL PROCEDURES}

\section{Transaminase estimations}

Serum glutamic pyruvic transaminase levels (SGPT) were determined in Hyderabad by a modification of the Reitman \& Frankel method ${ }^{18}$ using reagents purchased from Ortho Diagnostic Systems, Bombay.

\section{URINE ANALYSES}

Aliquots of urine were preserved with a crystal of thymol and stored at $0-4^{\circ} \mathrm{C}$ until shipment by air (without ref rigeration) to London for analysis. The regularity with which patients self-administered 
their prescribed Isoprodian treatment was assessed by testing urine samples with a combination of qualitative and quantitative methods for the presence of the isoniazid metabolites acetylisoniazid, isonicotinic acid and isonicotinylglycine; and for dapsone and its diazotisable metabolites. Dapsone estimations were initiated about half-way through the study to enable Isoprodian's ingestion to be compared with that of dapsone in the final phase of the study, when evidence from the acetylisoniazid and isonicotinic acid urine tests began to suggest that many patients were taking Isoprodian very irregularly.

All the analyses were carried out without reference to the origin of the specimen. Samples were tested qualitatively for acetylisoniazid by a minor modification of the Eidus \& Hamilton procedure, ${ }^{19}$ in which $0 \cdot 1 \mathrm{ml}$ aliquots were reacted on white procelain tiles with $0.1 \mathrm{ml} 10 \%$ aqueous potassium cyanide and $0.2 \mathrm{ml} 10 \%$ aqueous chloramine-T and the formation of a pink/brick-red colour noted within a few minutes. These tests were also carried out in Hyderabad. Isonicotinic acid and isonicotinyl glycine were detected qualitatively ${ }^{20}$ and estimated quantitively ${ }^{21}$ (as 'apparent' isonicotinic acid) by a modification of the Konig procedure. Highly positive samples gave an intense blue colour within 15-30 min. Among weakly positive or negative samples, the intake of nicotine could be judged according to the colours of the resultant reaction products. ${ }^{20,22}$

Creatinine concentrations were determined by the alkaline picrate procedure, while dapsone and its diazotisable metabolites were estimated using a modification of the Bratton \& Marshall method, ${ }^{23}$ and individual 'dapsone/creatinine $(\mathrm{D} / \mathrm{C})$ ratios' were calculated for each urine sample. The proportion of dapsone doses that had been ingested $(\mathrm{P})$ was calculated by comparing the mean $\mathrm{D} / \mathrm{C}$ ratios of appropriate groups of test urines $(\mathrm{T})$ with the mean for samples from patients when they were fully compliant $(\mathrm{C})$, after allowing for the contribution from blank urine (B) $(\mathrm{P}=\mathrm{T}-\mathrm{B} /$ C-B). ${ }^{21,23}$ ' $C$ ' and ' $D$ ' were estimated as 70.6 and $6 \cdot 3$, respectively, by averaging the $D / C$ ratios of sets of urine samples obtained from patients while they were being treated with Isoprodian that were either consistently positive for acetylisoniazid or consistently negative for isonicotinic acid.

Acid-labile isoniazid and acetylisoniazid concentrations were determined using picryl sulphonic acid and cyanogen chloride, respectively. ${ }^{24,25}$

The significance of apparent differences in the proportions of prescribed drug doses ingested by different groups of patients was analysed statistically using chi-squared tests for percentages of positive and negative urine tests, and t-tests for $\mathrm{D} / \mathrm{C}$ ratios.

\section{Results}

DRUG ACCEPTABILITY

\section{Treatment response}

As anticipated the clinical and bacteriological status of all the patients steadily improved during the 2 -year period of the study. Thus of the $21 \mathrm{LL}$ or BL patients who were initially smear-positive, 7 were smear-negative at the end of the investigation and the mean BI of the remaining 13 patients had fallen from $3 \cdot 3$ to $1 \cdot 9$ (1 patient absconded).

\section{Absence of hepatic toxicity}

There was no evidence of liver damage in the study; jaundice was not encountered and transaminase (SGPT) levels never exceeded 36 units/litre (mean 9 U/l).

\section{Gastrointestinal side-effects}

The prevalence and severity of the gastrointestinal side-effects attributed to prothionamide when the patients were treated with Isoprodian are summarized in Table 1. Side-effects were considered to 
Table 1. Acceptability of Isoprodian treatment and prevalence of gastrointestinal side-eff ects (numbers of patients)

\begin{tabular}{lcccrr}
\hline Side-effects* & No. & Defaulted & $\begin{array}{c}\text { Isoprodian } \\
\text { stopped } \ddagger\end{array}$ & $\begin{array}{c}\text { Completed } \\
\text { the study }\end{array}$ & $\begin{array}{c}\text { Good } \\
\text { compliance } \dagger^{*}\end{array}$ \\
\hline Acute $\S$ & $2(2) \uparrow$ & $2(2)$ & & $15(2)$ & $9(1)$ \\
None & $15(2)$ & & & $22(4)$ & $11(3)$ \\
Mild & $23(4)$ & 1 & & $8(2)$ & $5(1)$ \\
Moderate & $10(3)$ & $1(1)$ & 1 & $2(1)$ & $1(1)$ \\
Severe & $10(5)$ & $2(1)$ & $6(3)$ & $77(9)$ & $26(6)$ \\
\hline Total & $60(16)$ & $6(4)$ & $7(3)$ & 47 & \\
\hline
\end{tabular}

* For definitions see text.

$\dagger$ At least 3 of first 5 acetylisoniazid urine tests positive.

$\ddagger$ Replaced by dapsone plus monthly rifampicin.

$\S$ Ref used to continue in the study after ingesting the test Isoprodian dose.

I Female.

be mild when nausea or giddiness lasted for an hour or so after drug ingestion and subsided without the need for symptomatic treatment. They were graded as moderate when nausea, giddiness or occasional vomiting required treatment with antacids and/or antiemetics and described as severe when they also included anorexia, persisted throughout most of the day, and could not be totally controlled by antacids and antiemetics.

Two of the 60 enrolled patients refused to continue in the study because of the nausea experienced when they were given their test Isoprodian doses during the run-in phase. Moderate, severe or acute gastrointestinal side-effects were experienced by $22(37 \%)$ of the patients (Table 1$)$, were more common among the women (10 of 16) than among the men (12 of 44) $(p=0.01)$ as previously demonstrated, ${ }^{8}$ and led to Isoprodian being replaced by dapsone plus monthly rifampicin in 7 patients. Three of the 4 other patients who subsequently defaulted may have done so because of the side-effects they had experienced. The severity of gastrointestinal side-effects appeared not to be related to the ages of the patients. There were no other adverse reactions.

Table 2. Proportion of positive acetylisoniazid and isonicotinic acid urine-test results prior to and following the ingestion of test doses of Isoprodian

\begin{tabular}{lcccc}
\hline $\begin{array}{l}\text { Time } \\
\text { (h) }\end{array}$ & $\begin{array}{c}\text { No. } \\
\text { samples }\end{array}$ & $\begin{array}{c}\text { Acetylisoniazid } \\
\text { test } \\
\text { positive }(\%)\end{array}$ & $\begin{array}{c}\text { Isonicotinic acid } \\
\text { test } \\
\text { positive }(\%)\end{array}$ & $\begin{array}{c}\text { I/C ratios* } \\
\text { Geometric mean (range) }\end{array}$ \\
\hline 0 & 54 & $1(2)$ & $0(0)$ & $0 \cdot 27(0 \cdot 05-0 \cdot 98)$ \\
24 & 58 & $55(95)$ & $58(100)$ & $33 \cdot 0 \quad(12-147)$ \\
48 & 56 & $3(5)$ & $52(92)$ & $3 \cdot 3(0 \cdot 7-24)$ \\
72 & 58 & $0(0)$ & $33(57)$ & $0 \cdot 82(0 \cdot 29-3 \cdot 3)$ \\
96 & 58 & $0(0)$ & $9(16)$ & $0 \cdot 47(0 \cdot 22-1 \cdot 2)$ \\
\hline
\end{tabular}

* $\mu \mathrm{g}$ 'apparent' isonicotinic acid/mg creatinine. 
Table 3. Proportion of positive acetylisoniazid and isonicotinic acid urine-test results

\begin{tabular}{|c|c|c|c|c|}
\hline Prescribed treatment & $\begin{array}{l}\text { Mode sample } \\
\text { collection }\end{array}$ & $\begin{array}{l}\text { No. } \\
\text { samples }\end{array}$ & $\begin{array}{c}\text { Acetylisoniazid } \\
\text { test } \\
\text { positive }(\%)\end{array}$ & $\begin{array}{c}\text { Isonicotinic acid } \\
\text { test } \\
\text { positive }(\%)\end{array}$ \\
\hline Daily dapsone \pm monthly RMP & $\mathrm{H}+\mathrm{C}$ & 878 & $0(0)$ & $3(0 \cdot 3)$ \\
\hline \multirow[t]{2}{*}{$\begin{array}{l}\text { Daily Isoprodian } \\
\text { (Regimen A) }\end{array}$} & $\begin{array}{l}\mathrm{H} \\
\mathrm{C}\end{array}$ & $\begin{array}{l}197 \\
272\end{array}$ & $\begin{array}{l}115(58) \\
140(51)\end{array}$ & $\begin{array}{l}146(74) \\
177(65)\end{array}$ \\
\hline & $\mathrm{H}+\mathrm{C}$ & 469 & $255(54)$ & $323(69)$ \\
\hline \multirow[t]{2}{*}{$\begin{array}{l}\text { Daily Isoprodian }+ \text { monthly RMP } \\
\text { (Regimen B) }\end{array}$} & $\begin{array}{l}\mathrm{H} \\
\mathrm{C}\end{array}$ & $\begin{array}{l}187 \\
241\end{array}$ & $\begin{array}{l}108(58) \\
129(54)\end{array}$ & $\begin{array}{l}133(71) \\
160(66)\end{array}$ \\
\hline & $\mathrm{H}+\mathrm{C}$ & 428 & 237 (55) & $293(68)$ \\
\hline \multirow[t]{2}{*}{$\begin{array}{l}\text { Daily Isoprodian } \pm \text { monthly RMP } \\
\text { (Regimens A and B) }\end{array}$} & $\begin{array}{l}\mathrm{H} \\
\mathrm{C}\end{array}$ & $\begin{array}{l}384 \\
513\end{array}$ & $\begin{array}{l}223(58) \\
269(52)\end{array}$ & $\begin{array}{l}279(73) \\
337(66)\end{array}$ \\
\hline & $\mathrm{H}+\mathrm{C}$ & 897 & $492(55)$ & $616(69)$ \\
\hline $\begin{array}{l}\text { First } 24 \text { weeks } \dagger \\
\text { Second } 24 \text { weeks } \dagger\end{array}$ & $\begin{array}{l}\mathrm{H}+\mathrm{C} \\
\mathrm{H}+\mathrm{C}\end{array}$ & $\begin{array}{l}403 \\
360\end{array}$ & $\begin{array}{l}237(59) \\
199(55)\end{array}$ & $\begin{array}{ll}287 & (71) \\
234 & (65)\end{array}$ \\
\hline
\end{tabular}

* $\mathrm{H}$, home visit; $\mathrm{C}$, clinic visit.

$\dagger$ Results from those patients from whom at least 5 samples were collected during each period.

Table 4. Alternative methods of estimating the proportion of Isoprodian doses ingested

\begin{tabular}{|c|c|c|c|}
\hline Method & No. samples & Basis of calculation & $\begin{array}{l}\text { Overall proportion } \\
\text { doses ingested }\end{array}$ \\
\hline Acetylisoniazid ) & \multirow{3}{*}{897} & Percentage positive tests* & $55 \%$ \\
\hline \multirow{2}{*}{$\mathrm{I} / \mathrm{C}$ ratio } & & $\begin{array}{l}\text { No. doses taken during } \\
\text { previous } 48 \mathrm{~h}^{*}\end{array}$ & \\
\hline & & $\stackrel{1}{3 \cdot 3-33}$ & $51 \%$ \\
\hline \multirow{2}{*}{$\mathrm{D} / \mathrm{C}$ ratio } & \multirow{2}{*}{445} & Mean test ratio-blank & \\
\hline & & Mean compliant ratio-blank & $52 \%$ \\
\hline
\end{tabular}

$\mathrm{I}$, apparent isonicotinic acid $(\mu \mathrm{g} / \mathrm{ml}) ; \mathrm{C}$, creatinine $(\mathrm{mg} / \mathrm{ml}) ; \mathrm{D}$, dapsone plus diazotisable metabolites $(\mu \mathrm{g} / \mathrm{ml})$.

* Criteria based on results obtained with test doses of Isoprodian (Table 2).

\section{DRUG INGESTION}

\section{Collection of urine samples and creatinine estimations}

A total of 2130 urine samples were collected in the study, $99 \%$ before $2 \mathrm{pm}$, that is within $8 \mathrm{~h}$ of the time patients had been advised to swallow their dapsone or Isoprodian tablets. Forty-four of the samples with creatinine concentrations of less than $0 \cdot 1 \mathrm{mg} / \mathrm{ml}$ were discarded since such samples give inherently unreliable urine-test results. ${ }^{16}$ 
Table 5. Changes in patient compliance on switching from daily Isoprodian to daily dapsone treatment (numbers of patients)

\begin{tabular}{lcccccc}
\hline & & \multicolumn{5}{c}{ Change } \\
\cline { 3 - 6 } Compliance* & $\begin{array}{c}\text { Isoprodian } \\
\text { treatment }\end{array}$ & Worse & None & Better & Much better & $\begin{array}{c}\text { Dapsone } \\
\text { treatment }\end{array}$ \\
\cline { 3 - 6 } Excellent & 14 & 2 & 12 & - & - & 20 \\
Fair & 6 & 0 & 4 & 2 & - & 9 \\
Poor & 8 & 0 & 2 & 2 & 4 & 2 \\
Negligible & 6 & - & 3 & 0 & 3 & 3 \\
\hline All & 34 & 2 & 21 & 4 & 7 & 34 \\
\hline
\end{tabular}

* For definitions, see text.

Table 6. Correlation between estimates of Isoprodian compliance based on independent evidence for isoniazid and dapsone ingestion

\begin{tabular}{lcccc}
\hline Acetylisoniazid test & - & - & + & \\
Isonicotinic acid test & - & + & + & All \\
\hline $\begin{array}{l}\text { Dapsone/creatinine } \\
\text { ratios }(\mu \mathrm{g} / \mathrm{mg}) \\
\quad<10\end{array}$ & $139 *$ & 5 & 0 & 144 \\
$10-30$ & 14 & 27 & 18 & 59 \\
$>30$ & 0 & 12 & 230 & 242 \\
\hline All & $153(34 \%)$ & $44(10 \%)$ & $248(56 \%)$ & 445 \\
\hline Mean & $6 \cdot 2$ & $26 \cdot 0$ & $63 \cdot 4$ & $39 \cdot 9$ \\
(Range) & $(2 \cdot 1-16 \cdot 2)$ & $(7 \cdot 5-61)$ & $(16 \cdot 3-127)$ & $(2 \cdot 1-127)$ \\
Proportion ingested doses & $0 \%$ & $31 \%$ & $89 \%$ & $52 \%$ \\
\hline
\end{tabular}

* Numbers of samples.

Noting the presence or absence of nicotine metabolites when samples were found to be negative for isonicotinic acid provided evidence that the great majority of samples had been correctly labelled. Thus only $3 \%$ of the urine samples from the 24 patients who did not smoke or chew tobacco appeared to contain nicotine metabolites as compared with $98 \%$ of those from the 36 patients who did.

Reliability and interpretation of the urine-test procedures used to monitor the ingestion of the isoniazid component of the combined Isoprodian formulation

Only 4 false-positive acetylisoniazid or isonicotinic acid results were obtained on testing more than 900 samples collected from the patients while they were not on Isoprodian treatment (first lines of Tables 2 and 3). After the supervised ingestion of 2 tablets of Isoprodian, reliably positive results were obtained for about $24 \mathrm{~h}$ by the acetylisoniazid method and $48 \mathrm{~h}$ by the isonicotinic acid procedure (Table 2). By $48 \mathrm{~h}$, almost all samples gave negative results when tested for acetylsioniazid, indicating that the percentage of positive acetylisoniazid results from the study 
urines should give an approximate estimate of the proportion of ingested Isoprodian doses. An appreciable proportion of the urine samples obtained up to $96 \mathrm{~h}$ after ingestion of the supervised Isoprodian doses gave positive results when tested by the much more sensitive isonicotonic acid procedure and all the 492 study samples giving positive acetylisoniazid tests (Table 3 ) gave deep blue/purple colours when tested for isonicotinic acid.

Quantitative estimates of the ratios of isonicotinic acid plus isonicotinylglycine (as 'apparent' isonicotinic acid $)^{21}$ to creatinine (I/C) among the samples obtained pretreatment and 24, 48, 72 and $96 \mathrm{~h}$ after giving the test Isoprodian doses are summarized in Table 2. There was no evidence that the wide range of individual $\mathrm{I} / \mathrm{C}$ ratios at the different times represented consistent individual patterns of isoniazid metabolite excretion. Indeed, the most likely cause of such a variation, whether patients were rapid or slow acetylators of isoniazid, was excluded by determining their acetylator phenotype from the ratios of acetylisoniazid/acid-labile isoniazid ${ }^{26}$ among study samples giving positive qualitative acetylisoniazid results.

\section{Regularity of Isoprodian ingestion}

The results of the acetylisoniazid and isonicotinic acid tests are summarized in Table 3. The proportions of positive results among samples collected by means of surprise home visits were slightly higher than among those samples collected in the clinic $(p=0.1$ for acetylisoniazid and 0.025 for isonicotinic acid tests, respectively using pooled data from regimens A and B). Compliance was not influenced by supplementing Isoprodian treatment with monthly supervised doses of rifampicin, and did not decline significantly with time. The estimates of the proportion of Isoprodian doses ingested according to the percentage of positive acetylisoniazid tests, urinary isonicotinic acid/creatinine and dapsone/creatinine ratios are shown in Table 4.

\section{Comparison of Isoprodian and dapsone compliance}

There were sufficient data to compare the compliance of 34 of the patients after changing from Isoprodian to dapsone treatment (Table 5). For this comparison 4 arbitrary grades of compliance
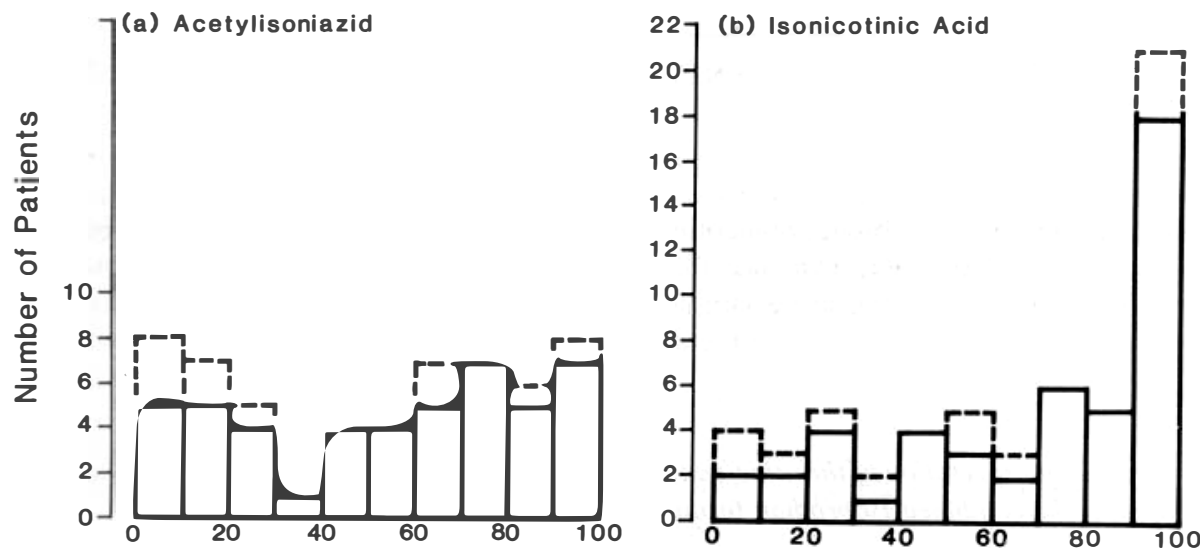

\section{Percentage of Positive Urine Tests}

Figure 1. Numbers of patients with varying percentages of (a) positive acetylisoniazid urine-test results, and (b) positive isonicotinic acid urine-test results. Solid lines illustrate the results from the 47 patients from whom at least 10 samples were analysed (total 851 samples), dotted lines show the results from all 58 patients (total 917 samples). 


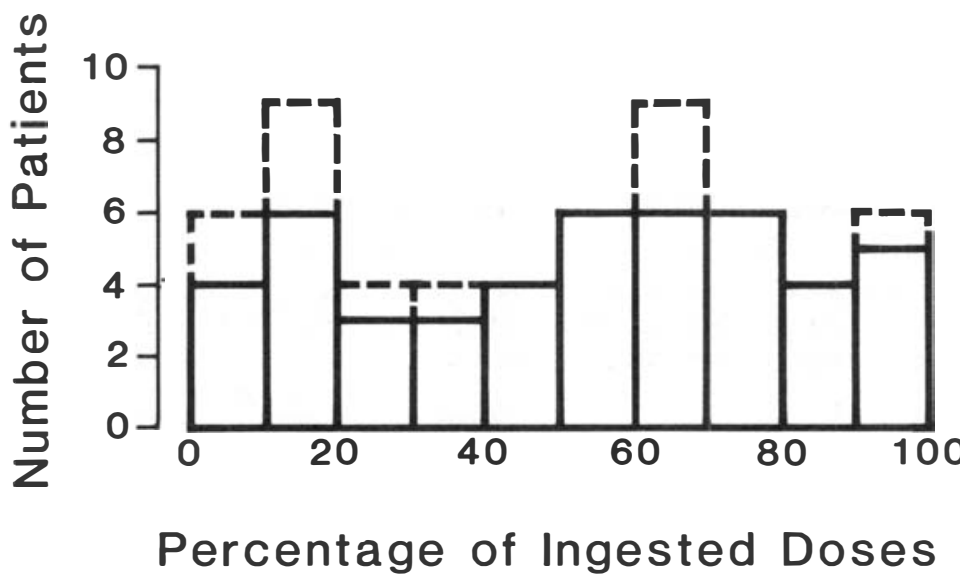

Figure 2. Numbers of patients with varying estimated proportions of ingested Isoprodian doses. Solid lines illustrate the results from the 47 patients from whom at least 10 samples were analysed, dotted lines show the results from all 58 patients.

were used; excellent, fair, poor and negligible, according to whether the mean $\mathrm{D} / \mathrm{C}$ ratios of their urine samples were more than $40,20-40,10-20$, or less than $10 \mu \mathrm{g} / \mathrm{mg}$, respectively. Patients in these 4 categories would have ingested on average about $90 \%, 30 \%, 10 \%$ and fewer than $2 \%$, respectively, of their prescribed drug doses. Compliance improved significantly when patients were switched from Isoprodian to dapsone, equivalent to an increase in the overall proportion of prescribed doses ingested from $48 \%$ to $60 \%$. Furthermore, it was particularly noteworthy that, of the 7 patients whose compliance had most markedly improved when changing from Isprodian to dapsone treatment, 4 had previously experienced severe gastrointestinal side-effects.

Regularity of Isoprodian self-administration: correlation between the results obtained by different urine tests

The excellent correlation between the dapsone and isoniazid metabolite findings of individual samples are summarized in Table 6 . Thus $97 \%$ of the 144 samples with $\mathrm{D} / \mathrm{C}$ ratios of less than $10 \mu \mathrm{g} /$ $\mathrm{mg}$, indicating that dapsone had not been ingested within the previous 4 days, ${ }^{27}$ gave negative results when tested for both acetylisoniazid and isonicotinic acid. Similarly, $95 \%$ of the 242 samples with $\mathrm{D} / \mathrm{C}$ ratios of more than $30 \mu \mathrm{g} / \mathrm{mg}$ were positive for both the isoniazid metabolites.

\section{Individual variation in patient compliance}

One of the most striking findings of the investigation was the enormous interindividual variation in patient compliance (Figures 1 and 2). Considering patients from whom at least 10 samples were analysed, 12 provided samples giving more than $80 \%$ positive acetylisoniazid tests in contrast with 10 other patients with fewer than $20 \%$ positive results (Figure 1(a)). Similarly considering the isonicotinic acid tests (Figure 1(b)), in 18 patients more than $90 \%$ of their urine samples gave positive results, while fewer than $30 \%$ of the samples from 8 other patients were read as positive. However, patients could not be grouped merely into good and poor compliars; there was a continuous spectrum of compliance. This spectrum was confirmed (Figure 2) when the proportions of ingested Isoprodian doses were calculated from the $\mathrm{I} / \mathrm{C}$ ratios of the samples. 
Table 7. Influence of age and gastrointestinal side-eff ects on compliance

\begin{tabular}{|c|c|c|c|c|c|c|}
\hline \multirow[b]{3}{*}{ Parameter } & \multirow{3}{*}{$\begin{array}{l}\text { Number } \\
\text { patients }\end{array}$} & \multirow{3}{*}{$\begin{array}{l}\text { Total number } \\
\text { samples }\end{array}$} & \multicolumn{2}{|c|}{$\%$ Samples positive for } & \multirow{2}{*}{\multicolumn{2}{|c|}{$\%$ Doses ingested }} \\
\hline & & & \multirow[b]{2}{*}{ acetylisoniazid } & \multirow{2}{*}{$\begin{array}{l}\text { isonicotinic } \\
\text { acid }\end{array}$} & & \\
\hline & & & & & $\mathrm{I} / \mathrm{C}^{*}$ & $\mathrm{D} / \mathrm{C}^{*}$ \\
\hline \multicolumn{7}{|l|}{ Age } \\
\hline Less than 30 & $16(15) \dagger$ & $255(105)$ & $65) 62$ & $80\} 76$ & $60\} 58$ & $62) 62$ \\
\hline $30-40$ & $21(17)$ & 297 (146) & $60\} 62$ & $72\} 76$ & $56\}^{58}$ & $62\} 62$ \\
\hline Over 40 & $21(20)$ & $345(194)$ & 43 & 57 & 40 & 38 \\
\hline \multicolumn{3}{|c|}{$p$ value (over 40 vs 40 or less) } & $<0.001$ & $<0.001$ & $<0.001$ & $<0.001$ \\
\hline \multicolumn{7}{|l|}{ Side-effects $\ddagger$} \\
\hline None & $15(15)$ & $274(153)$ & $63)$ & $76)$ & $55)$ & 507 \\
\hline Mild & $23(23)$ & 378 (192) & $52\} 58$ & $67\} 71$ & $49\} 54$ & $48\} 52$ \\
\hline Moderate & $10(7)$ & $151(60)$ & $65 \int$ & $74)$ & $61 \int$ & $70 \int$ \\
\hline Severe & $10(6)$ & $94(40)$ & 27 & 46 & 29 & 33 \\
\hline \multicolumn{3}{|c|}{$p$ value (severe $v s$ none to moderate) } & $<0.001$ & $<0.001$ & $<0.001$ & 0.07 \\
\hline
\end{tabular}

* I/C: apparent isonicotinic acid/creatinine method; D/C: dapsone/creatinine method.

$\dagger$ For D/C method.

$\ddagger$ For definitions see text.

\section{Factors affecting compliance}

Patients aged over 40 ingested Isoprodian less regularly than younger patients (Table 7) and the severity of gastrointestinal side-effects had a marked influence on compliance. Thus patients with severe symptoms ingested only about half as many Isoprodian doses as the other patients. A multiple regression analysis of the results obtained from the 47 patients from whom at least 10 urine samples had been analysed demonstrated that compliance declined with both increasing age and previous length of treatment, but was not influenced by their disease classification and sex, or whether or not they smoked or chewed tobacco. Compliance appeared to be related to the $\mathrm{mg} / \mathrm{kg}$ dosage of thioamides given, since it improved with increasing body-weight.

\section{Discussion}

\section{REGULARITY OF ISOPRODIAN INGESTION}

The proportion of prescribed Isoprodian doses ingested within the $24 \mathrm{~h}$ prior to collecting the urine samples was estimated to be $55 \%, 51 \%$ or $52 \%$ according to whether the acetylisoniazid, isonicotinic acid/creatinine or dapsone/creatinine methods, respectively were employed (Table 4). The agreement between the results obtained by these three independent methods was very encouraging and it may therefore be confidently concluded that just over half the prescribed Isoprodian doses were ingested. This is a significantly smaller proportion $(p<0.001)$ than that of the ethionamide and prothionamide doses estimated to have been ingested $(73 \%)$ in the earlier pilot study. ${ }^{16}$ The most likely explanation for the different levels of compliance in the two studies is the enormous individual variability in patient compliance with the consequence that a larger proportion of better compliars may fortuitously have been included among the 12 patients included in the pilot study. 
The overall compliance of the patients who did not experience gastrointestinal side-effects (about 55\%) is quite typical of that found in previous studies carried out in Af rica and Asia, when dapsone was administered alone. ${ }^{28,29}$ The excellent acceptability of isoniazid makes it most unlikely that its inclusion in Isoprodian tablets has an adverse influence on compliance.

\section{INDIVIDUAL VARIABILITY IN PATIENT COMPLIANCE}

Almost all previous studies of dapsone compliance among leprosy patients (reviewed ${ }^{28,29}$ ) have only analysed single urine samples from individual patients. The results of this study clearly show that the drug self-administration of leprosy patients does not separate into 2 clear-cut modes (Figures 1 and 2); therefore, it is impossible to assess overall compliance on the basis of a single urine test. Previous compliance studies carried out among tuberculosis patients also provided evidence of a continuous spectrum in the individual regularities of drug self-administration. ${ }^{30-33}$ Further evidence for a continuous spectrum of compliance has recently come from a completely new approach to measuring drug taking ${ }^{34}$ in which the use of pilocarpine eye drops to reduce intraocular pressure ${ }^{35}$ or an experimental aerosolized medication to control asthma, ${ }^{36}$ was monitored electronically by means of microswitch devices.

\section{COLLECTING URINE SAMPLES FOR COMPLIANCE MONITORING}

Organizing and making surprise home visits to collect urine samples is very time consuming for the staff, and a nuisance for the patients. An important result of this study was the finding that the proportions of positive urine samples collected during the surprise home visits were similar to those of samples collected in the clinic (Table 3). This suggests that the impending occasion of the clinic visit does not appreciably alter the daily pattern of individual compliance. The much more conveniently obtained clinic specimens can therefore be employed without risk of biasing the outcome of compliance investigations. This finding is in accord with the only cismprehensive study of this question ever undertaken in the whole field of compliance research-an investigation of the taking of isoniazid and $p$-amino-salicylic acid (PAS) by Chinese tuberculosis outpatients in Hong Kong. ${ }^{33}$

\section{ADVERSE SIDE-EFFECTS}

The lack of evidence of hepatic toxicity was a welcome finding, in view of the experience of other groups of workers with combinations of prothionamide, rifampicin and dapsone $e^{9-12}$ and the 2 cases of jaundice encountered in the pilot study. Although gastrointestinal effects may be a less serious manifestation of thioamide toxicity than liver damage, they were nevertheless extremely important. Such side-effects were almost entirely responsible for the fact that about a quarter of the enrolled patients failed to complete the study (Table 1). Furthermore, the presence of severe gastrointestinal side-effects appears to have greatly discouraged the taking of prothionamide, as evidenced by the much poorer compliance of patients with such symptoms (Table 7), and the marked improvement in their self-medication when they were transferred to dapsone treatment (Table 5). As a consequence, it was concluded that only 1 of the 10 patients who suffered f rom severe gastrointestinal side-effects completed the study having taken sufficient Isoprodian for unequivocal therapeutic benefit (Table 1).

\section{IMPLICATIONS FOR THE TREATMENT OF LEPROMATOUS PATIENTS WITH THIOAMIDE- CONTAINING REGIMENS}

The results of this study indicate that daily prothionamide should only be prescribed when its compliance can be monitored. This can be conveniently achieved using isoniazid formulations such 
as those previously prepared for the pilot compliance study with $6 \mathrm{mg}$ isoniazid per tablet or capsule and testing urine samples by the isonicotinic acid method, ${ }^{16}$ or, as in the current study, employing the commercial combined formulation Isoprodian and the Eidus \& Hamilton acetylisoniazid tiletest method. ${ }^{19}$

Since variations in individual patient compliance appear to be continuous (Figures 1 and 2), several urine samples need to be tested from each patient in order to obtain a reasonable assessment of their drug taking. An analysis of the acetylisoniazid and dapsone urine-test results from the current study demonstrated that the testing of 5 urine samples per patient should be sufficient for this purpose and that when 3 of the first 5 urine samples collected during the Isoprodian treatment phase gave positive acetylisoniazid tests, enough prothionamide and dapsone had been ingested to be certain of therapeutic benefit. In the current study it was concluded that as a result of either poor compliance or discontinuation of Isoprodian treatment because of gastrointestinal intolerance, only $26(43 \%)$ of the 60 patients originally enrolled into the study had ingested sufficient Isoprodian for unequivocal therapeutic benefit (Table 1).

Although attempts to exhort poorly compliant patients to take their treatment more regularly should not be discouraged, past experience suggests that they are rarely likely to succeed. Since supervised intermittent treatment with the thioamides will almost certainly be ineffective, ${ }^{15}$ one can only recommend that poorly compliant patients be treated with regimens containing the maximum amount of supervised treatment. Such a regimen is regimen A in the THELEP-sponsored Field Trials being conducted in South India where $600 \mathrm{mg}$ doses of clofazimine and rifampicin are given under supervison on 2 consecutive days each month and self-administered daily dapsone treatment is supplemented by injections of $225 \mathrm{mg}$ acedapsone once every 2 months. ${ }^{37}$

\section{Acknowledgments}

We wish to thank Saarstickstoff Fatol, Schiffweiler, West Germany for the gift of the Isoprodian tablets which was kindly arranged through the courtesy of Professor E Freerksen. The home visits were undertaken by Mrs Deveena Prabhaker, Mr Daniel Jones and Mr Syed Yousuff Jani. We are also grateful to Mr Shyam Rao who measured the serum transaminase levels and carried out the acetylisoniazid urine tests in Hyderabad, and would like to thank Dr J M H Pearson and Professor L Levy for their many helpful comments. Dhoolpet Leprosy Research Centre is managed by Victoria Hospital, Dichpalli, in collaboration with the Medical Research Council (of Great Britain), and also receives support from the British Leprosy Relief Association (LEPRA).

\section{References}

1 WHO Study Group. Chemotherapy of leprosy for control programmes. WHO, Technical Report Series, 1982; No. 675 .

2 Colston MJ, Ellard GA, Gammon PT. Drugs for combined therapy: Experimental studies on the antileprosy activity of ethionamide and prothionamide, and a general review. Lepr Rev, 1978; 49: 115-26.

${ }^{3}$ Colston MJ, Hilson GRF, Banerjee DK. The 'Proportional bactericidal test'. A method for assessing the bactericidal activity of drugs against $M$. leprae in mice. Lepr Rev, 1978; 49: 7-15.

4 Shepard CC, Jenner PJ, Ellard GA, Lancaster RD. An experimental study of the antileprosy activity of a series of thioamides in the mouse. Int $J$ Lepr, 1985; 53: 587-94.

5 Jenner PJ, Ellard GA. High-performance liquid chromatographic determination of ethionamide and prothionamide in body fluids. J Chromatogr, 1981; 225: 245-51.

6 Jenner PJ, Ellard GA, Gruer PJK, Aber VR. A comparison of the blood levels and urinary excretion of ethionamide and prothionamide in man. J Antimicrob Chemother, 1984; 13: 267-77.

7 Jenner PJ, Smith SE. Plasma levels of ethionamide and prothionamide in man following intravenous a nd oral dosages. Lepr Rev, 1987; 58: 31-7.

${ }^{8}$ Fox W, Robinson DK, Tall R, Mitchison DA, Kent PW, Macfadyen DM. A study of the intolerance to ethionamide, including a comparison with prothionamide, and of the influence of a vitamin B-complex additive in prophylaxis. Tubercle, 1969; 50: 125-43. 
9 Ji Baohong, Chen Jiakun, Wang Chenmin, Xia Guang. Hepatoxicity of combined therapy with rifampicin and daily prothionamide for leprosy. Lepr Rev, 1984; 55: 283-9.

10 Pattyn SR, Janssens L, Bourland J, Saylan T, Davies EM, Grillone S, Feracci C. Hepatotoxicity of the combination of rifampicin-ethionamide in the treatment of multibacillary leprosy. Int J Lepr, 1984; 52: $1-6$.

${ }^{11}$ Cartel JL, Millan J, Guelpa-Lauras CC, Grosset JH. Hepatitis in leprosy patients treated by a daily combination of dapsone, rif ampin and a thioamide. Int J Lepr, 1983; 51: 461-5.

12 Cartel J, Naudillon Y, Artus J, Grosset J. Hepatotoxicity of the daily combination of $5 \mathrm{mg} / \mathrm{kg}$ prothionamide and $10 \mathrm{mg} / \mathrm{kg}$ rifampin. Int J Lepr, 1985; 53: 15-18.

13 Colston MJ, Hilson GRF, Lancaster RD. Intermittent chemotherapy of experimental leprosy in mice. Am J Trop Med Hyg, 1980; 29: 103-8.

14 Ellard GA. Rationale of the multidrug regimens recommended by a World Health Organization Study Group on chemotherapy of leprosy for control programs. Int J Lepr, 1984; 52: 395-401.

15 Guelpa-Lauras CC, Grosset J, Constant-Desportes M, Brucker G. Nine cases of rifampin-resistant leprosy. Int J Lepr, 1984; 52: 101-2.

16 Stanley JNA, Pearson JMH, Ellard GA. Ethionamide, prothionamide and thiacetazone self-administration. Studies of patient compliance using an isoniazid-marked formulation. Lepr Rev, 1986; 57: 9-18.

17 Shepard CC, Levy L, Fasal P. Further experience with the rapid bactericidal effect of rifampin on Mycobacterium leprae. Am J Trop Med Hyg, 1974; 23: 1120-4.

18 Reitman S, Frankel S. A colorimetric method for the determination of serum glutamic oxalacetic and glutamic pyruvic transaminases. Am J Clin Path, 1957; 28: 56-63.

19 Eidus L, Hamilton EJ. A new method for the determination of N-acetyl isoniazid in urine of ambulatory patients. Am Rev Resp Dis, 1964; 89: 587-8.

${ }^{20}$ Stanley JNA, Pearson JMH, Ellard GA. An investigation of dapsone compliance using an isoniazid-marked formulation. Lepr Rev, 1983; 54: 317-25.

21 Ellard GA, Jenner PJ, Downs PA. An evaluation of the potential use of isoniazid, acetylisoniazid and isonicotinic acid for monitoring the self-administration of drugs. Br J Clin Pharmacol, 1980; 10: 369-81.

22 Peach H, Ellard GA, Jenner PJ, Morris RW. A simple inexpensive urine test for smoking. Thorax, 1985; 40: 351-7.

23 Ellard GA, Gammon PT, Helmy HS, Rees RJW. Urine tests to monitor the self-administration of dapsone by leprosy patients. Am J Trop Med Hyg, 1974; 23: 464-70.

24 Ellard GA, Gammon PT, Polansky F, Viznerova A, Havlik I, Fox W. Further studies on the pharmacology of a slow-release matrix preparation of isoniazid (Smith \& Nephew HS 82) of potential use in the intermittent treatment of tuberculosis. Tubercle, 1973; 54: 57-66.

25 Ellard GA, Gammon PT, Tiitinen H. Determination of the acetylator phenotype using matrix isoniazid. Tubercle, 1975; 56: 203-9.

${ }^{26}$ Eidus L, Hodgkin MM, Schaeffer O, Jessamine AG. Distribution of isoniazid inactivators determined in Eskimos and Canadian college students by a urine test. Rev Can Biol, 1974; 33: 117-23.

27 Ellard GA. Profile of urinary dapsone/creatinine ratios af ter oral dosage with dapsone. Lepr Rev, 1980; 51: 229-36.

28 Ellard GA. Drug compliance in the treatment of leprosy. Lepr Rev, 1981; 52: 201-13.

29 Huikeshoven H. Patient compliance with dapsone administration in leprosy. Int J Lepr, 1981; 49: 228-58.

30 Tuberculosis Chemotherapy Centre, Madras. A concurrent comparison of isoniazid plus PAS with three regimens of isoniazid alone in the domiciliary treatment of pulmonary tuberculosis in South India. Bull WHO, 1960; 23: 535-85.

31 East African/British Medical Research Council. Isoniazid with thiacetazone (thioacetazone) in the treatment of pulmonary tuberculosis in East Africa-Fifth investigation. Tubercle, 1970; 51: 123-51.

32 Singapore Tuberculosis Services/Brompton Hospital/British Medical Research Council. A controlled clinical trial of the role of thiacetazone-containing regimens in the treatment of pulmonary tuberculosis in Singapore. Tubercle, 1971; 52: 88-116.

33 Hong Kong Treatment Services/British Medical Research Council Investigation. A study in Hong Kong to evaluate the role of pretreatment susceptibility tests in the selection of regimens of chemotherapy for pulmonary tuberculosis-Second Report. Tubercle, 1971; 55: 169-92.

34 Norell SE. Methods of assessing drug compliance. Acta Med Scand (Suppl), 1984; 683: 35-40.

${ }^{35}$ Kass MA, Meltzer DW, Gordon M, Cooper D, Goldberg J. Compliance with topical pilocarpine treatment. Am J Opthalmol, 1986; 101: 515-23.

36 Spector SL, Kinsman R, MacWhinney H, Siegel SC, Racheef sky GS, Katz RM, Rohr AS. Compliance of patients with asthma with an experimental aerosolized medication: Implications for controlled medical trials. J Allergy Clin Immunol, 1986; 1: 65-70.

37 UNDP/World Bank/WHO Special Programme for Research and Training in Tropical Diseases. Tropical Disease Research: A Global Partnership. Maurice J, Pearce NM, (eds) 1987, WHO, Geneva. 
NEWS AND NOTES

\section{Monoclonal antibodies to Mycobacterium leprae}

As part of the UNDP/World Bank/WHO Special Programme for Research and Training in Tropical Diseases, the Scientific Working Group on Immunology of Leprosy (IMMLEP) organized a workshop in June 1984 to characterize the specificity and reaction patterns of several murine monoclonal antibodies to Mycobacterium leprae.

Coded aliquots of 22 monoclonal antibodies that had been generated in six different laboratories had previously been sent to seven laboratories for independent analysis by a variety of methods, including enzymelinked immunosorbent assay (ELISA), radioimmunoasssay, electrophoretic and/or immunoblotting techniques, crossed immunoelectrophoresis and indirect immunofluorescence. The results, as agreed upon by the international group of investigators participating in the workshop, have been presented in detail elsewhere, and are summarized here.

Of the 22 monoclonal antibodies tested, 10 were found to be specific for $M$. leprae, with another 10 antibodies cross-reactive for one or more of the 25 mycobacterial species tested. The remaining two monoclonal antibodies were found to be specificf or a protein of relative molecular mass 95000 present in normal armadillo liver homogenates.

These monoclonal antibodies should prove extremely useful in the development of new methods for the immunodiagnosis of leprosy, in the identification of immunogenic $M$. leprae-specific gene products produced using recombinant DNA techniques, and finally in helping to characterize those $M$. leprae antigens that are important for the stimulation of cellular immunity.

Subject to available reserves, aliquots of the $M$. leprae-specific monoclonal antibodies will be made available to qualified investigators by IMMLEP, upon receipt of a short (one-page) summary of the experiments to be carried out with the antibodies. Requests should be addressed to Leprosy, World Health Organization, 1211 Geneva 27, Switzerland.

\section{Gandhi Memorial Leprosy Awards 1988}

From the Hindustan Times, New Delhi, January 30, 'President R. Venkataraman today called individuals, voluntary organizations and government to work together to consolidate the achievements made till now in the field of leprosy eradication, and carry forward the initiative through 'to a dynamic programme of detection, treatment and rehabilitation.'

Speaking at the International Gandhi Memorial Leprosy Award Function, he said, while we have made great improvements in case of detection systems, we must move towards active and thorough coverage of villages. Detection cannot be left to voluntary reporting. Likewise, in the area of treatment there is need for continuous research on the causes and cure of leprosy and camp studies on the results so far achieved.

The President gave away the International Gandhi Memorial Award for Leprosy instituted by the Gandhi Memorial Leprosy Foundation consisting of Rs 1,000,000 in cash, a medallion and a citation to Prof essor Thachakkadu Natesa Jagadisan from India and Dr Ma Haide from China. The award is given in recognition of distinguished service in the field of leprosy for not less than 10 years and contribution to any aspect of leprosy work, resulting in amelioration of sufferings of leprosy patients and in their assimilation in society as normal and usef ul members.

\section{THELEP International Workshop on Chemotherapy Research of Leprosy}

The Chemotherapy of Leprosy (THELEP) Scientific Working Group of the UNDP/World Bank/WHO Special Programme for Research and Training in Tropical Diseases organized in November 1986 in Osaka, Japan, in collaboration with the Sasakawa Memorial Health Foundation, an International Workshop on Experimental Chemotherapy of Leprosy. Because additional clinical and field trials were required to improve the treatment of leprosy, and because there is a need to strengthen the research capability of prospective centres for such research through training, the THELEP Steering Committee organized, as a follow-up to the Osaka Workshop, an International Workshop on Chemotherapy Research of Leprosy from 1 to 15 December 1987 at the All Africa Leprosy \& Rehabilitation Training Centre (ALERT), Addis Ababa, Ethiopia. The objectives of the Workshop were: 1, to improve the knowledge of the participants through a systematic review of the modern concepts of chemotherapy and the methods of clinical research and field trials; and 2, to promote research activities in chemotherapy of leprosy.

Seventeen senior medical doctors from nine leprosy endemic countries participated in the Workshop as 'trainees'. Twelve doctors or scientists from both the THELEP Scientific Working Group and ALERT served as faculty members. The Workshop was indeed an intensive training course which covered all fields of chemotherapy of leprosy as well as related areas such as leprosy reactions, nerve damage, neuritis and their treatment. The evaluation of the Workshop indicates that it was successf ul. Source: Dr Ji Baohong, Secretary, THELEP Steering Committee, WHO, Geneva, Switzerland. 